\title{
DL-3-n-butylphthalide protects endothelial cells against advanced glycation end product-induced injury by attenuating oxidative stress and inflammation responses
}

\author{
CHANG-YUN LIU ${ }^{1 *}$, ZHEN-HUA ZHAO ${ }^{2 *}$, ZHI-TING CHEN ${ }^{1}$, CHUN-HUI CHE $^{1}$, ZHANG-YU ZOU $^{1}$, \\ XIAO-MIN WU ${ }^{1}$, SHENG-GEN CHEN ${ }^{1}$, YUAN-XIAO LI ${ }^{1}$, \\ HAN-BIN LIN $^{1}$, XIAO-FAN WEI ${ }^{1}$, JIE YOU $^{3}$ and HUA-PIN HUANG ${ }^{1}$ \\ ${ }^{1}$ Department of Neurology, Union Hospital; ${ }^{2}$ Department of Neurology, Fujian Provincial Hospital, \\ Fujian Medical University; ${ }^{3}$ Department of Endocrinology, Union Hospital, Fujian Medical \\ University, Fujian Endocrinology Institute, Fuzhou, Fujian 350001, P.R. China
}

Received February 9, 2016; Accepted February 14, 2017

DOI: $10.3892 /$ etm.2017.4784

\begin{abstract}
Endothelial dysfunction, regarded as a key step in the pathophysiological course of diabetic vascular complications, is initiated and deteriorated by advanced glycation end products (AGEs). DL-3-n-butylphthalide (DL-NBP) has been proven to have protective effects on neurons and vascular endothelial cells against ischemic and anoxic damage. The aim of the present study was to investigate whether NBP is able to attenuate AGE-induced endothelial dysfunction in vitro, and also elucidate the possible underlying mechanism. An injury model of human umbilical vein endothelial cells (HUVECs) induced by AGEs $(200 \mu \mathrm{g} / \mathrm{ml})$ was established. The results demonstrated that pretreatment with NBP (1-100 $\mu \mathrm{M})$ significantly increased HUVEC viability and inhibited the apoptosis induced by AGEs. In addition, AGEs stimulated the expression levels of the receptor for AGEs protein and the downstream protein nuclear factor- $\mathrm{kB}$ in HUVECs, which were inhibited by pretreatment with NBP. Furthermore, it significantly reduced reactive oxygen species generation and the level of the inflammatory cytokines, intercellular cell adhesion molecule-1 and monocyte chemotactic protein-1, in HUVECs mediated by AGEs. The current findings indicated that NBP attenuated AGE-induced endothelial dysfunction by ameliorating inflammation and oxidative stress responses.
\end{abstract}

Correspondence to: Dr Chang-Yun Liu, Department of Neurology, Union Hospital, Fujian Medical University, 29 Xinquan Road, Fuzhou, Fujian 350001, P.R. China

E-mail: 13365910778@189.cn

${ }^{*}$ Contributed equally

Key words: DL-3-n-butylphthalide, advanced glycation end products, endothelial cells, inflammation, oxidative stress, apoptosis

\section{Introduction}

Macrovascular diseases, such as myocardial infarction, brain ischemic infarction and arterial occlusive disease of lower extremities, are the most important complications in diabetes, which is an independent risk factor for atherosclerosis. Endothelial dysfunction has been regarded as one of the main causes involved in the pathogenesis of vascular complications in diabetes (1). Advanced glycation end products (AGEs) are produced by the non-enzymatic glycation and oxidation reactions of glucose or other reducing sugars with proteins, lipids and nucleotides. It had been suggested that AGEs trigger and aggravate the endothelium damage in diabetic complications (2). Previous evidence has linked AGEs with the development of atherosclerosis in diabetes, regardless of the diabetic status (3).

The 1-isomer of 3-n-butylphthalide (NBP) is extracted from the seeds of Chinese celery, Apiumgraveolens Linn., and synthesized DL-NBP had been commonly used in acute ischemic stroke in China (4). In a recent study, DL-NBP was demonstrated to improve vascular cognitive impairment caused by subcortical ischemic small vessel disease (5). Its multiple neuroprotective effects were due to reduction of oxidative stress (6), blocking of inflammatory reactions and reduction of neuronal apoptosis (7). It had been proven that DL-NBP also exerts a protective effect on endothelial cells by suppressing the production of peroxynitrite, superoxide and nitric oxide in an acute hypoxia model (8). Notably, these protective effects were also observed in other disease models, not caused by hypoxia or ischemic injury. For instance, DL-NBP prevented oxidative damage and reduced mitochondrial dysfunction in an $\mathrm{MPP}^{+}$-induced cellular model of Parkinson's disease (9). Furthermore, it attenuated amyloid- $\beta$-induced inflammatory responses in astrocytes via the nuclear factor- $\kappa \mathrm{B}(\mathrm{NF}-\kappa \mathrm{B})$ signaling pathway (10). Thus, it is hypothesized that NBP may alleviate endothelial dysfunction induced by AGEs.

The aim of the present study was to investigate whether NBP presents protective effects on endothelial cells against AGE-induced injury. In addition, the molecular mechanism 
underlying the action of NBP on AGE-induced endothelial dysfunction was studied. The findings of the present study may provide the therapeutic potentiality of NBP on preventing the development of diabetic vascular complications.

\section{Materials and methods}

Reagents and materials. DL-NBP (purity, 99.6\%) was obtained from Shijiazhuang Pharmaceutical Group Co., Ltd. (Shijiazhuang, China). NBP was dissolved in dimethylsulfoxide (DMSO). Dulbecco's modified Eagle's medium (DMEM) and fetal bovine serum were obtained from Thermo Fisher Scientific, Inc. (Waltham, MA, USA). 3-(4,5-Dimethylthiazol-2-yl)-2,5-diphenyltetrazolium bromide (MTT) and the oxidation-sensitive probe 2,7-dichlorofluorescin diacetate (DCFH-DA) were purchased from Sigma-Aldrich (Merck KGaA, Darmstadt, Germany). Antibodies against receptor for AGEs (RAGE, no. MAB1145), NF- $\kappa B$, (no. MAB5078), intercellular cell adhesion molecule-1 (ICAM-1, no. BBA3), monocyte chemotactic protein 1 (MCP-1, no. MAB279), B-cell lymphoma-2 (Bcl-2, no. MAB8272), Bcl-2-associated X protein (Bax, no. 2281-MC) and cleaved caspase-3 (no. MAB835) were obtained from R\&D Systems, Inc. (Minneapolis, MN, USA). The antibody against $\beta$-actin (no. A00702) was from GenScript (Piscataway, NJ, USA). Horseradish peroxidase-conjugated secondary antirabbit (no. A0545) and antimouse (no. A0168) antibodies were obtained from Sigma Aldrich (Merck KGaA). The Hoechst staining kit (no. C0003) was purchased from Beyotime Institute of Biotechnology (Dalian, China).

Preparation of AGEs. Bovine serum albumin (BSA; $5 \mathrm{~g}$ ) and D-glucose $(9 \mathrm{~g})$ were dissolved in $0.2 \mathrm{M}$ phosphate-buffered saline (PBS). The mixture was filtrated through $0.22 \mu \mathrm{m}$ microporous film and incubated at $37^{\circ} \mathrm{C}$ for 3 months. Next, any unincorporated glucose was removed by dialysis against PBS at the end of the reaction. The content of AGEs was detected by using a Gemini EM fluorescence microplate reader (Molecular Devices, Sunnyvale, CA, USA) at excitation/emission wavelengths of 370/440 nm. Then, AGEs were diluted to a concentration of $1 \mathrm{mg} / \mathrm{ml}$ for the Bradford Protein Assay (no. PA115-01; Tiangen Biotech Co., Ltd., Beijing, China) with BSA used as a standard, as previously described (11). Non-glycated BSA was used as a blank control and was incubated in the same conditions without D-glucose.

Cell and cell culture. Human umbilical vein endothelial cells (HUVECs, no. PCS-100-010), obtained from the American Type Culture Collection (Manassas, VA,USA), was maintained in basal DMEM supplemented with $10 \%$ fetal bovine serum, low-glucose and $100 \mathrm{U} / \mathrm{ml}$ penicillin/streptomycin. Cells were grown on plastic cell culture flasks in a cell incubator at $37^{\circ} \mathrm{C}$ in a humidified atmosphere with $5 \% \mathrm{CO}_{2}$. The medium was changed every $24 \mathrm{~h}$. Cells at 2-4 passages were used in the experiments until they generated a 70-80\% confluent layer.

HUVECs were seeded onto 96-well plates at a concentration of $1 \times 10^{5}$ cells $/ \mathrm{ml}$ and were then treated with $0,0.1,1,10$ or $100 \mu \mathrm{M}$ NBP for $0.5 \mathrm{~h}$. Next, the cells were incubated with $200 \mu \mathrm{g} / \mathrm{ml}$ AGEs or control BSA for $48 \mathrm{~h}$. HUVECs were divided into six groups, as follows: i) normal group, incubated with BSA only; ii) AGEs group, incubated with $200 \mu \mathrm{g} / \mathrm{ml}$ AGEs only; iii) $0.1 \mu \mathrm{M} \mathrm{NBP} \mathrm{+} \mathrm{AGEs} \mathrm{group;} \mathrm{iv)} 1 \mu \mathrm{M} \mathrm{NBP} \mathrm{+}$ AGEs group; v) $10 \mu \mathrm{M}$ NBP + AGEs group; and vi) $100 \mu \mathrm{M}$ $\mathrm{NBP}+$ AGEs group.

Cell viability and apoptosis assessment. Cell viability in the different groups was determined using the colorimetric MTT assay. In brief, MTT $(0.5 \mathrm{mg} / \mathrm{ml})$ was added to the medium. After $4 \mathrm{~h}$ of incubation, the medium with MTT was removed, and $100 \mu 1$ DMSO was subsequently added to each well. The absorbance at $490 \mathrm{~nm}$ was measured using a microplate reader (BioTek Instruments, Inc., Winooski, VT, USA). The cell viability of the vehicle-treated control group that was not exposed to AGEs or NBP was defined as $100 \%$.

For the detection of cell apoptosis, cells were stained with $1 \mu \mathrm{g} / \mathrm{ml}$ Hoechst 33,258 for $10 \mathrm{~min}$ at $37^{\circ} \mathrm{C}$. Subsequently, images of the cells were captured under a laser scanning confocal microscope (BioTek Instruments, Inc.). Apoptotic cells were defined as those with condensed or fragmented nuclei with strong bright Hoechst 33258 staining.

Measurement of intracellular reactive oxygen species (ROS) generation. The intracellular ROS production was measured with the oxidation-sensitive probe DCFH-DA. In brief, HUVECs were incubated with DCFH-DA $(10 \mu \mathrm{mol} / \mathrm{l})$ at $37^{\circ} \mathrm{C}$ for $30 \mathrm{~min}$. Subsequently, the HUVECs were washed with cold PBS, collected and subjected to flow cytometry (BD FACSCalibur; Becton Dickinson, San Jose, CA, USA) for ROS assay. The ROS production was determined by the fluorescence intensity at an excitation wavelength of $488 \mathrm{~nm}$ and an emission wavelength of $525 \mathrm{~nm}$. The fluorescence was expressed as a percentage of the total area.

Western blot analysis. Following incubation with $200 \mu \mathrm{g} / \mathrm{ml}$ AGEs or control BSA at $37^{\circ} \mathrm{C}$ in a humidified $5 \% \mathrm{CO}_{2}$ incubator for $48 \mathrm{~h}$, HUVECs were removed the culture medium, washed with PBS and lysed with radioimmunoprecipitation assay buffer (no. C1051; Applygen Technologies Inc., Beijing, China) supplemented with 1 protease inhibitor cocktail tablet (no. 04693132001; Roche Diagnostics GmbH, Mannheim, Germany) per $50 \mathrm{ml}$ of buffer. The protein concentration was determined using the Bradford Protein Assay (No. PA115-01, Tiangen Biotech Co., Ltd., Beijing, China), with BSA used as a standard. A total of $100 \mu \mathrm{g}$ protein was transferred to each slice and subjected to $15 \%$ sodium dodecyl sulfate-polyacrylamide gel electrophoresis. The samples were then transferred to a nitrocellulose film, and blocked using 5\% skim milk in Tris-buffered saline/Tween 20 (TBST) buffer. Subsequently, they were incubated with the primary antibodies against RAGE (1:400), NF-кB (1:500), ICAM-1 (1:400), MCP-1 (1:500), Bcl-2 (1:500), Bax (1:500), cleaved caspase-3 (1:300) and $\beta$-actin $(1: 2,000)$ at $4^{\circ} \mathrm{C}$ overnight. The membranes were washed and then exposed to the horseradish peroxidase-conjugated secondary antibodies $(1: 2,000)$ for $1 \mathrm{~h}$ at room temperature. Following three washes in TBST, the bands were detected with enhanced chemiluminescence detection reagents (Pierce; Thermo Fisher Scientific, Inc.). The density of each band was analyzed using Quantity One version 4.6.2 (Bio-Rad Laboratories, Inc., Hercules, CA, USA). 


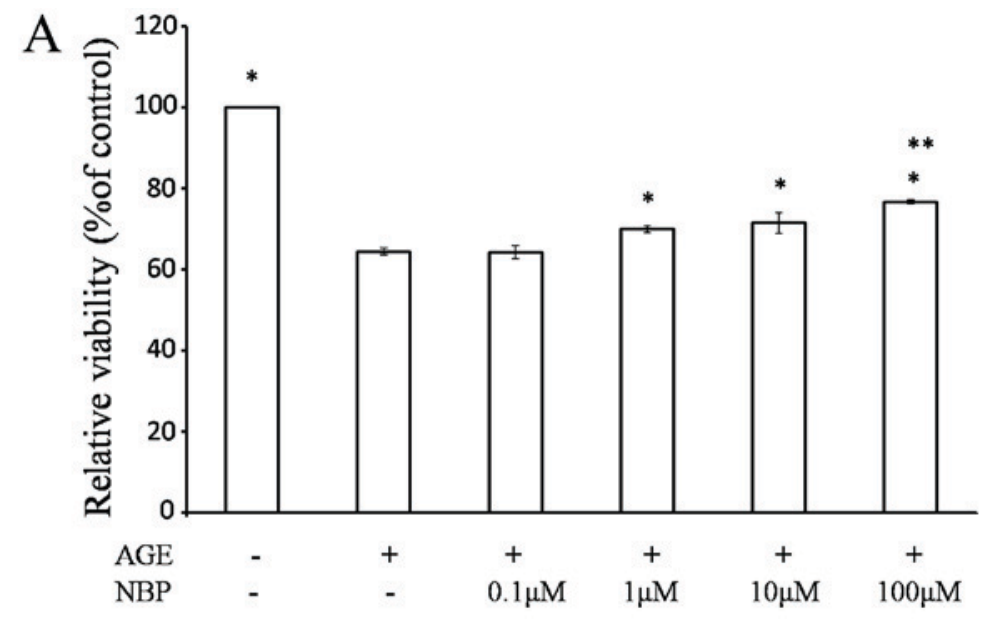

B
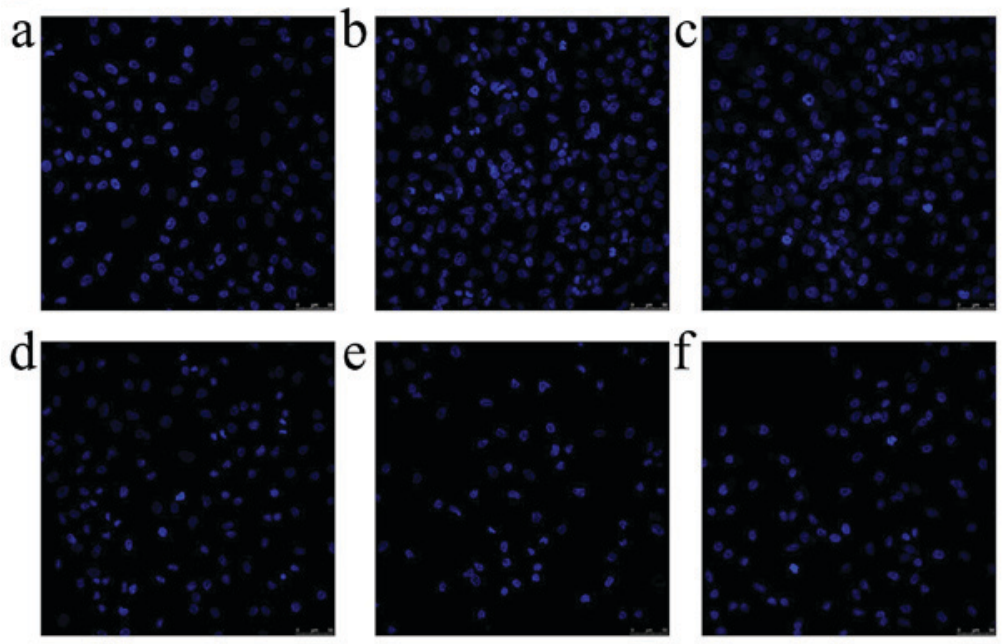

Figure 1. Effect of NBP on the cellular viability and apoptosis of HUVECs induced by AGEs. (A) HUVEC viability detected by MTT assay. Cells incubated with various concentrations of NBP for $48 \mathrm{~h}$ showed increased viability, with the effect being more evident at high content of NBP. Data are presented as the means \pm standard deviation. ${ }^{*} \mathrm{P}<0.05$ vs. the AGE-treated group; ${ }^{* *} \mathrm{P}<0.05$ vs. the 0.1 and $10 \mu \mathrm{M}$ NBP groups. (B) HUVEC apoptosis was determined according to the morphological changes of nuclear condensation and/or fragmentation using Hoechst 33258 staining in the: (a) Normal (vehicle-treated); (b) AGE only; (c) $0.1 \mu \mathrm{M} \mathrm{NBP}$; (d) $1 \mu \mathrm{M} \mathrm{NBP}$; (e) $10 \mu \mathrm{M} \mathrm{NBP}$; and (f) $100 \mu \mathrm{M}$ NBP groups (magnification, $\mathrm{x} 400$ ). HUVEC, human umbilical vein endothelial cell; AGEs, advanced glycation end products; NBP, 3-n-butylphthalide.

Statistical analysis. All data in this study are expressed as the mean \pm standard deviation. The statistical significance of differences among groups was analyzed using one-way analysis of variance with the SPSS version 19.0 software (IBM Corp., Armonk, NY, USA). Differences with P-values of $<0.05$ were considered to be statistically significant. Experiments were performed in triplicate and repeated in three separate cell preparations.

\section{Results}

NBP reduces the cytotoxicity and apoptosis of HUVECs induced by AGEs. The cell viability of HUVECs was measured by MTT assay. As shown in Fig. 1A, cell viability in the AGEs group was significantly decreased to $64.40 \pm 0.82 \%$, when compared with the normal group treated with BSA $(\mathrm{P}<0.001)$. However, following pretreatment with $0.1,1,10$ and $100 \mu \mathrm{M}$ NBP, the cell viability was gradually increased to $64.23 \pm 1.61$, $69.90 \pm 0.81,71.43 \pm 2.61$ and $76.67 \pm 0.51 \%$, respectively. NBP treatment significantly reduced the AGE-induced cell death in a dose-dependent manner at doses of $\geq 1 \mu \mathrm{M}(\mathrm{P}<0.05$; Fig. 1A).
HUVEC apoptosis was determined according to the morphological changes in the nuclei that were examined using Hoechst 33258 staining. Condensed or fragmented nuclei with strong bright Hoechst 33258 staining were evidently observed in the AGE-treated group in laser scanning confocal microscope. As shown in Fig. 1B, the fluorescence decreased with the increase of NBP concentration, indicating reduction in apoptosis.

Effects of NBP on apoptosis-associated protein expression in HUVECs induced by AGEs. The expression levels of the apoptosis-associated proteins Bax, $\mathrm{Bcl}-2$ and cleaved caspase-3 were evaluated by western blot analysis. Treatment with AGEs increased the cleaved caspase-3 protein expression and the ratio of $\mathrm{Bax} / \mathrm{Bcl}-2$ proteins in HUVECs. However, pretreatment with NBP inhibited the apoptosis of HUVECs by regulating the expression of the apoptosis-associated proteins. As shown in Fig. 2, cleaved caspase-3 protein expression was significantly reduced in the 10 and $100 \mu \mathrm{M} \mathrm{NBP}$ groups $(\mathrm{P}<0.05)$, compared with the AGEs group. In addition, Bax protein expression was significantly reduced even at the lowest treatment dose 


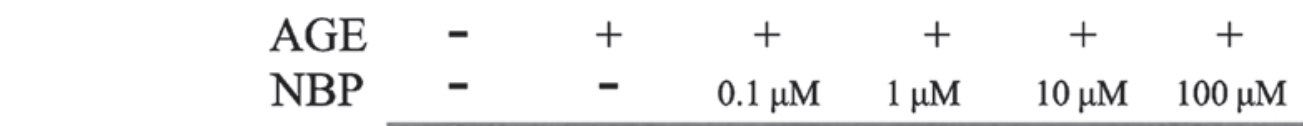

Bcl-2

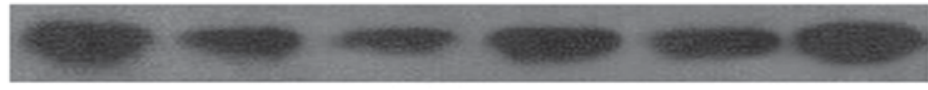

$\operatorname{Bax}$

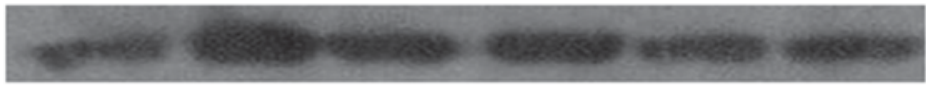

\section{Cleaved caspase-3}

\section{$\beta$-actin}
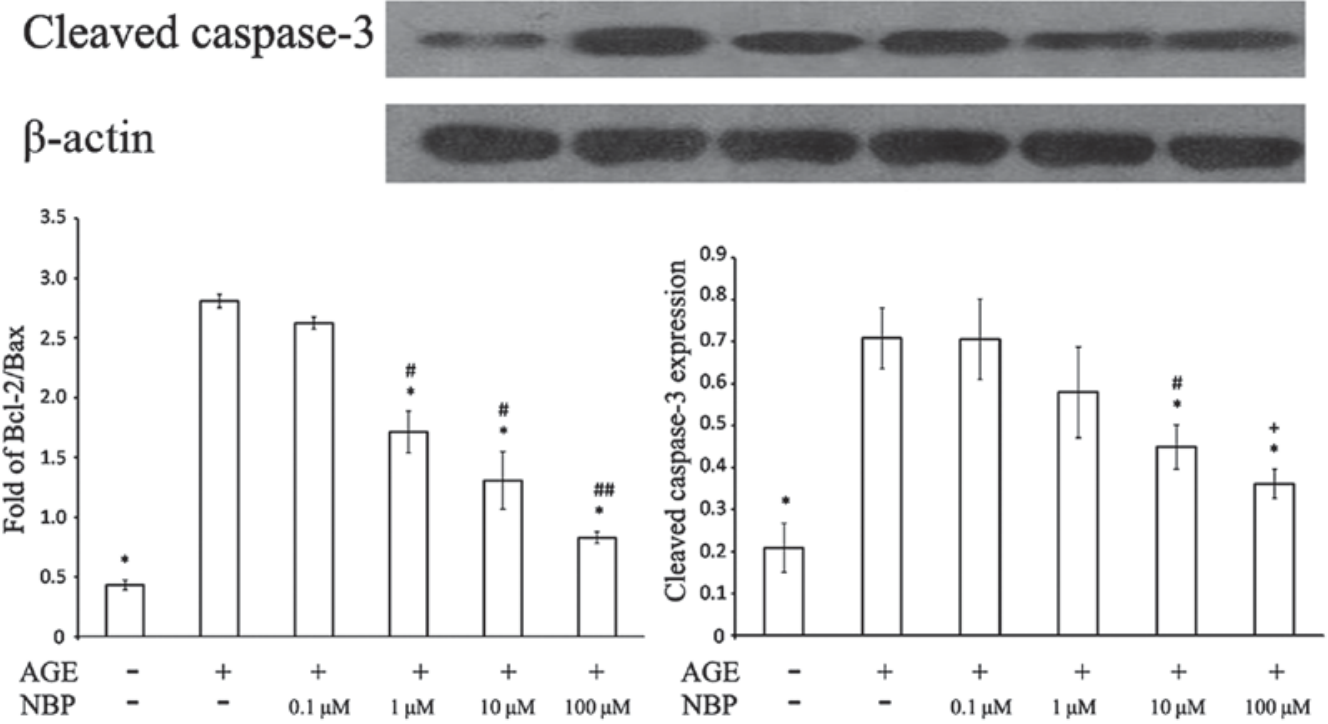

Figure 2. Effect of NBP on protein expression levels of cleaved caspase-3, Bcl-2 and Bax in HUVECs induced by AGEs was determined by western blot analysis. HUVECs were incubated with various concentrations of NBP for $48 \mathrm{~h}$. Treatment with AGEs induced the expression of cleaved caspase-3 and Bax, and inhibited Bcl-2 protein expression. The ratio of Bcl-2/Bax and cleaved caspase-3 expression were reduced as NBP content increased. The data are presented as the mean \pm standard error. ${ }^{*} \mathrm{P}<0.05$ vs. AGE-treated group; ${ }^{\#} \mathrm{P}<0.05$ vs. $0.1 \mu \mathrm{M}$ NBP group; ${ }^{\# \#} \mathrm{P}<0.05$ vs. $0.1,1$ and $10 \mu \mathrm{M} \mathrm{NBP}$ groups; ${ }^{+} \mathrm{P}<0.05$ vs. 0.1 and $1 \mu \mathrm{M}$ NBP groups. HUVEC, human umbilical vein endothelial cell; AGEs, advanced glycation end products; NBP, 3-n-butylphthalide; Bcl-2, B-cell lymphoma-2; Bax, Bcl-2-associated X protein.



Figure 3. Effect of NBP on expression levels of RAGE and NF-kB proteins in HUVECs induced by AGEs was determined by western blot analysis. HUVECs were incubated with various concentrations of NBP for $48 \mathrm{~h}$. AGEs induced the expression of RAGE and NF-kB proteins, which was downregulated as NBP content increased. The data are presented as the mean \pm standard error. ${ }^{*} \mathrm{P}<0.05$ vs. AGE-treated group ${ }^{* *} \mathrm{P}<0.05$ vs. $0.1 \mu \mathrm{M}$ NBP group; ${ }^{*} \mathrm{P}<0.05$ vs. 0.1 and $1 \mu \mathrm{M}$ NBP groups; ${ }^{\# /} \mathrm{P}<0.05$ vs. $0.1,1$ and $10 \mu \mathrm{M}$ NBP groups. HUVEC, human umbilical vein endothelial cell; AGEs, advanced glycation end products; NBP, 3-n-butylphthalide; RAGE, receptor for AGE; NF, nuclear factor. 

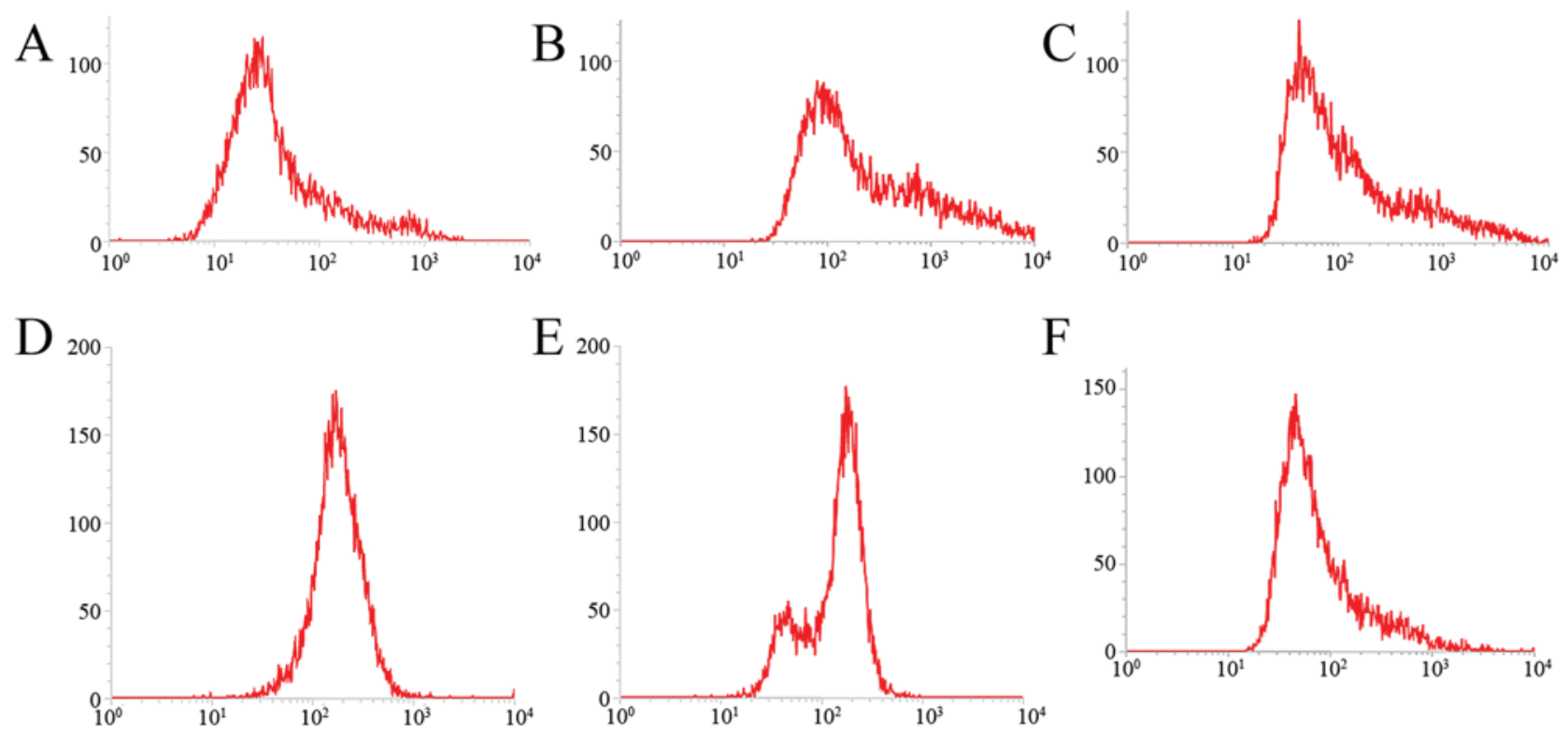

$\mathrm{E}_{200}$
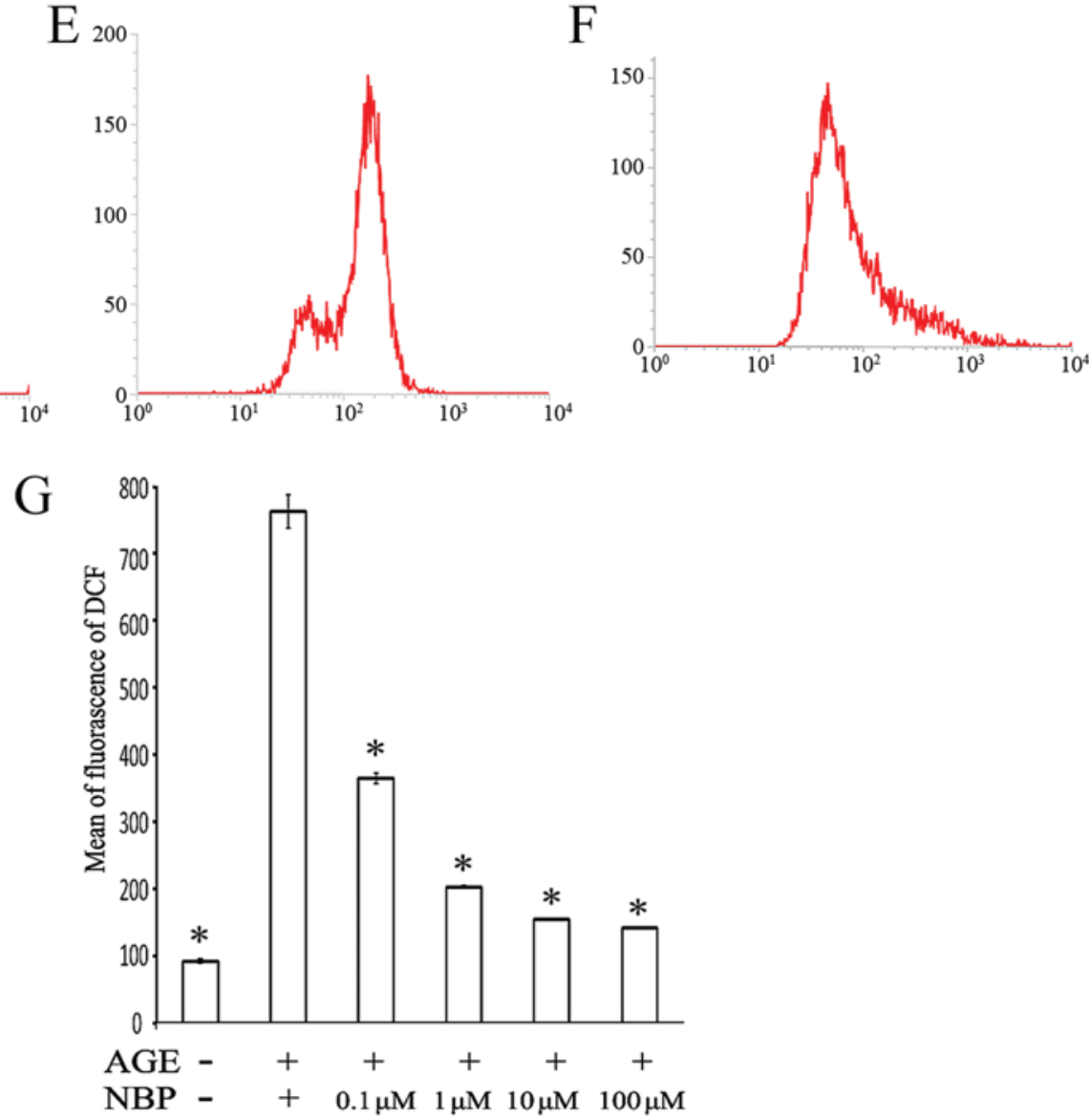

Figure 4. NBP attenuates the AGE-induced intracellular ROS production in HUVECs, as determined by the measuring the mean fluorescence of DCF by flow cytometry. (A) Normal (vehicle-treated), (B) AGE-treated, (C) $0.1 \mu \mathrm{M} \mathrm{NBP,}$, (D) $1 \mu \mathrm{M} \mathrm{NBP,} \mathrm{(E)} 10 \mu \mathrm{M}$ NBP, and (F) $100 \mu \mathrm{M}$ NBP groups. (G) Quantified flow cytometry results. The data are presented as the mean \pm standard error. "P $<0.001$ vs. AGE-treated group. HUVEC, human umbilical vein endothelial cell; AGEs, advanced glycation end products; NBP, 3-n-butylphthalide; ROS, reactive oxygen species.

of $0.1 \mu \mathrm{M}$ NBP $(\mathrm{P}<0.05)$. By contrast, significant increase in $\mathrm{Bcl}-2$ protein expression was observed in the 10 and $100 \mu \mathrm{M}$ NBP groups $(\mathrm{P}<0.05)$, compared with the AGE-treated group. The ratio of $\mathrm{Bax} / \mathrm{Bcl}-2$ was significantly reduced as the content of NBP increased $>0.1 \mu \mathrm{M}(\mathrm{P}<0.05)$. These findings suggested that NBP inhibited apoptosis by regulating the AGE-induced expression levels of apoptosis-associated proteins in HUVECs.

Effect of NBP on AGE-induced RAGE and $N F-\kappa B$ protein expression levels in HUVECs. Western blot analysis was performed to further evaluate the effect of NBP on AGE-induced overexpression of RAGE and NF- $\kappa \mathrm{B}$ proteins. As shown in Fig. 3, compared with the normal group, treatment with AGEs significantly increased the expression levels of RAGE and NK- $\kappa$ B. Pre-incubation with 10 and $100 \mu \mathrm{M}$ NBP significantly downregulated the AGE-induced RAGE protein overexpression in HUVECs $(\mathrm{P}<0.05)$, compared with the AGEs group. Furthermore, the expression of downstream protein $\mathrm{NF}-\kappa \mathrm{B}$ was significantly inhibited following exposure to 10 and $100 \mu \mathrm{M}$ NBP $(\mathrm{P}<0.05)$. These observations suggested that NBP may ameliorate AGE-induced endothelial dysfunction via the RAGE/NF- $\kappa \mathrm{B}$ pathway.

NBP inhibits AGE-induced cellular oxidative stress. RAGE can activate diverse signal transduction cascades and downstream pathways, in which ROS generation serves an important role in AGE-induced injury in endothelial cells (12). In the present study, ROS generation was measured on the basis of the fluorescence intensity of DCF detected by flow cytometry. As shown in Fig. 4, after $48 \mathrm{~h}$ of AGEs treatment, ROS release in the AGEs group was 7.7-folds that of the normal control $(763.0 \pm 24.8$ vs. $92.7 \pm 3.2$, respectively; $\mathrm{P}<0.001)$. The relative ROS production in the groups treated with NBP at $0.1,1,10$ and $100 \mu \mathrm{M}$ concentration 


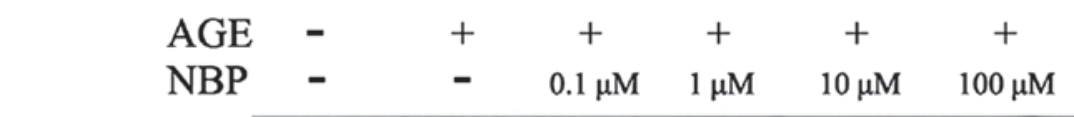

ICAM-1

MCP-1

$\beta$-actin
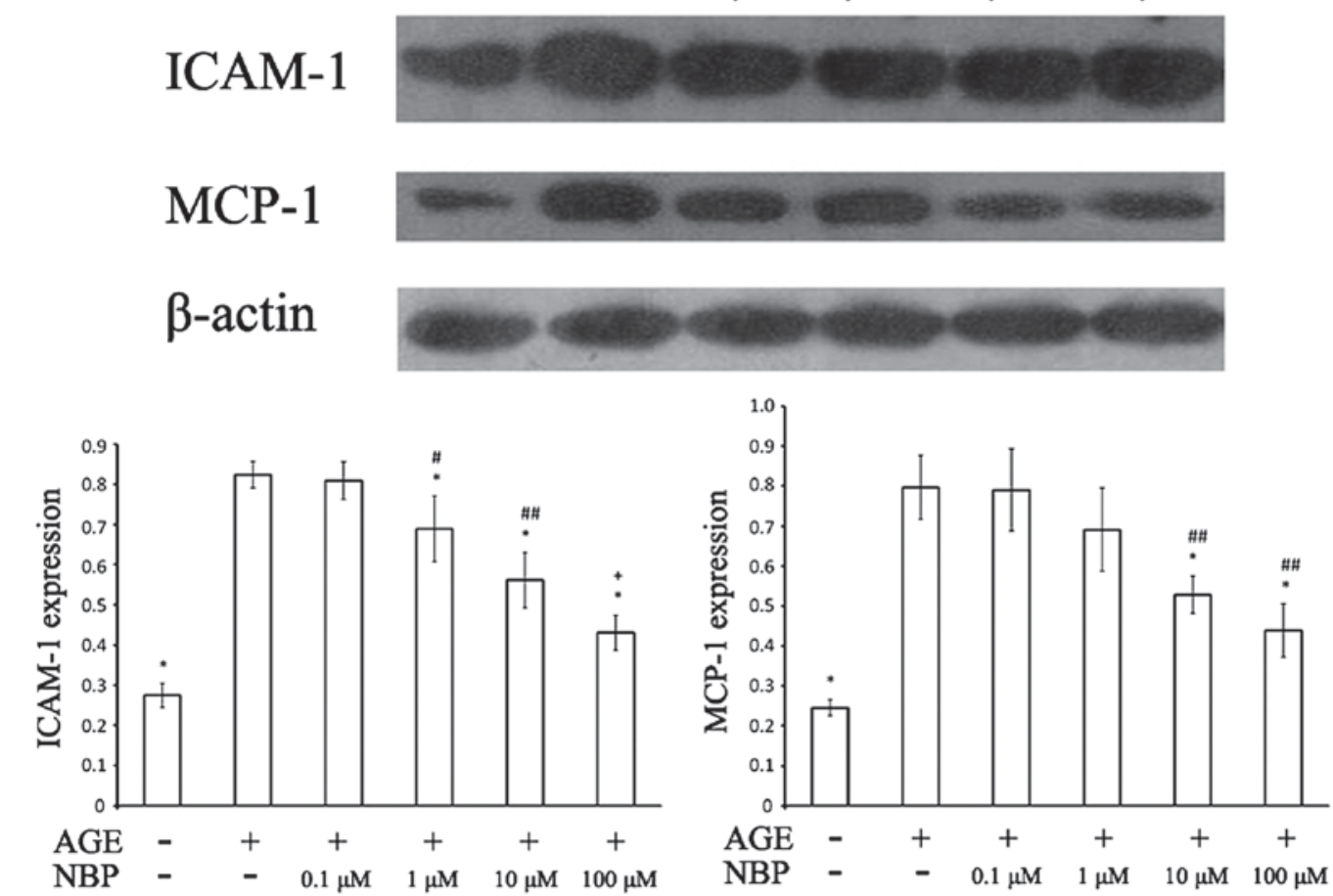

Figure 5. NBP downregulated the expression of proinflammatory factors in HUVECs induced by AGEs, as demonstrated by western blot analysis. HUVECs were incubated with various content of NBP for $48 \mathrm{~h}$. AGEs induced overexpression of ICAM-1 and MCP-1, which were downregulated as NBP content increased. The data are presented as the mean \pm standard error. ${ }^{*} \mathrm{P}<0.05$ vs. AGE-treated group; ${ }^{*} \mathrm{P}<0.05$ vs. $0.1 \mu \mathrm{M}$ NBP group; ${ }^{\# \prime} \mathrm{P}<0.05$ vs. 0.1 and $1 \mu \mathrm{M}$ NBP groups; ${ }^{+} \mathrm{P}<0.05$ vs. $0.1,1$ and $10 \mu \mathrm{M}$ NBP groups. HUVEC, human umbilical vein endothelial cell; AGEs, advanced glycation end products; NBP, 3-n-butylphthalide; ICAM-1, intercellular cell adhesion molecule-1 (ICAM-1); MCP-1, monocyte chemotactic protein 1.

was significantly reduced to $365.7 \pm 7.8(47.93 \%), 203.3 \pm 2.1$ (26.65\%), $155.0 \pm 1.0(20.31 \%)$ and $141.7 \pm 1.5(18.57 \%)$, respectively, when compared with the AGEs group $(\mathrm{P}<0.05)$. Therefore, pretreatment with NBP may significantly reverse the ROS overproduction.

NBP ameliorates HUVEC dysfunction by downregulating the expression of proinflammatory factors. The expression of adhesion molecules, such as ICAM-1, is responsible for the monocyte adhesion to the endothelium (13). The monocytes then migrate to the inner layer of the artery, due to the action of MCP-1 (14). In the present study, western blot analysis was used to investigate the expression of these two inflammatory factors linked with atherosclerosis. As shown in Fig. 5, HUVECs in the normal group expressed low levels of ICAM-1 and MCP-1; by contrast, HUVECs stimulated with AGEs demonstrated significantly upregulated expression levels of ICAM-1 and MCP-1. This effect on ICAM-1 expression was inhibited by NBP at a dose of $\geq 1.0 \mu \mathrm{M}(\mathrm{P}<0.05)$. The expression level of MCP-1 also showed similar amelioration after treatment with NBP at $\geq 10 \mu \mathrm{M}(\mathrm{P}<0.05)$.

\section{Discussion}

The neuroprotective effects of NBP on reducing the damage of acute hypoxia and ischemia have been previously highlighted (4). In the present study, it was demonstrated that NBP has a potential protection activity on AGE-induced endothelial dysfunction in HUVECs. NBP may attenuate AGE-mediated oxidative stress responses and inflammation via inhibiting RAGE/NF- $\kappa \mathrm{B}$ axis activation.

Diabetes is an independent risk factor for atherosclerosis, resulting in ischemic stroke, coronary disease and arterial occlusive disease of lower extremities. The mechanism of initiation and deterioration of vascular complications in diabetes remains unclear. However, the concept of hyperglycemic memory that is vastly accepted in several clinical studies suggested that AGEs perform an important role in diabetic vascular complications $(15,16)$. AGEs bind to the AGE receptors on vascular endothelial cells and induce the production of ROS (12), which directly damage endothelial cells via apoptosis. The activation of RAGE with the increase of ROS may also cause multiple pathological changes in gene expression by activating the pleiotropic transcription factor $\mathrm{NF}-\kappa \mathrm{B}$ and increasing the adhesion of inflammatory cells to the endothelium $(17,18)$. These influences lead to endothelial dysfunction, which is recognized as the initial step in the atherosclerotic process (19). Therefore, ameliorating endothelial dysfunction is one of the critical therapeutic strategies for preventing or slowing the initiation and progression of vascular disease in diabetes mellitus.

Oxidative stress is closely correlated with pathophysiological damage in endothelial dysfunction $(20,21)$. AGEs bind to the special receptors, such as RAGE and galectin-3, on the surface of endothelial cells (22). As the main effect receptor, RAGE is typically expressed at low levels and may be upregulated by positive feedback when its ligands accumulate (23). The interaction of AGEs and its receptor results 
in the generation of intracellular ROS through activation of RAGE (24,25). Consistent with these findings, the present study obtained similar results, observing that AGEs resulted in upregulation of RAGE expression and ROS release when compared with the normal group in HUVECs. Treatment of HUVECs with NBP inhibited the AGE-induced RAGE overexpression at the protein level. Reduction of ROS generation was confirmed by flow cytometry, and the damage of ROS was inhibited by ameliorating apoptosis. All these effects were performed at an evident dose-dependent manner, suggesting that AGE-induced cellular oxidative stress injury in HUVECs may be suppressed by NBP treatment via inhibition of the RAGE pathway.

Endothelial inflammation is the initial step in atherosclerosis and participates in all stages of atherosclerosis (26). AGEs interacting with RAGE results in activation of a number of pathways, such as ROS (27), mitogen-activated protein kinase kinases (28), protein kinase C (29), and phosphatidylinositol-3 kinase (30) in vascular endothelia. These signaling pathways initiate and sustain the activation of $\mathrm{NF}-\kappa \mathrm{B}$, leading to vascular inflammatory injury (11). $\mathrm{NF}-\kappa \mathrm{B}$ is considered as a primary regulator of inflammatory processes, and its activation leads to high expression of adhesion molecules, including ICAM-1 and MCP-1, in endothelial cells. ICAM-1 facilitates adhesion to endothelial cells and trans-endothelial migration of leukocytes (31). The activation of adhesion molecules results in the expression of MCP-1, promoting the monocyte migration to the intima (32). The activity of MCP-1 also increases the platelet adhesion (33). The results of the present study suggested that AGEs significantly upregulated the expression levels of MCP-1 and ICAM-1 in HUVECs via the activation of NF- $\kappa$ B. Pretreatment of HUVECs with NBP markedly inhibited the NF- $\kappa \mathrm{B}$ expression, while the levels of MCP-1 and ICAM-1 were also downregulated. These findings indicated that NBP may attenuate endothelial damage via inhibiting proinflammatory response.

In conclusion, the present study suggested that NBP may block AGE-induced endothelial dysfunction by inhibiting inflammation response and oxidative stress. NBP may be used for the potential prevention and treatment of diabetic vascular complications at an appropriate dosage.

\section{Acknowledgements}

This study was supported by grants from the Young and Middle-aged Backbone Foundation of Fujian Province (grant no. 2013-ZQN-ZD-16), the Natural Science Foundation of Fujian Province (grant no. 2014J01321), and the National Key Clinical Specialist (Geriatrics Department) Construction Programs of China (no grant number; awarded 2013-2014).

\section{References}

1. Naka KK, Papathanassiou K, Bechlioulis A, Kazakos N, Pappas K, Tigas S, Makriyiannis D, Tsatsoulis A and Michalis LK: Determinants of vascular function in patients with type 2 diabetes. Cardiovasc Diabetol 11: 127, 2012.

2. Capellini VK, Celotto AC, Baldo CF, Olivon VC, Viaro F, Rodrigues AJ and Evora PR: Diabetes and vascular disease: Basic concepts of nitric oxide physiology, endothelial dysfunction, oxidative stress and therapeutic possibilities. Curr Vasc Pharmacol 8: 526-544, 2010.
3. Peppa M, Uribarri J and Vlassara $\mathrm{H}$ : The role of advanced glycation end products in the development of atherosclerosis. Curr Diab Rep 4: 31-36, 2004.

4. Cui LY, Zhu YC, Gao S, Wang JM, Peng B, Ni J, Zhou LX, He J and Ma XQ: Ninety-day administration of dl-3-n-butylphthalide for acute ischemic stroke: A randomized, double-blind trial. Chin Med J (Engl) 126: 3405-3410, 2013.

5. Jia J, Wei C, Liang J, Zhou A, Zuo X, Song H, Wu L, Chen X, Chen S, Zhang J, et al: The effects of DL-3-n-butylphthalide in patients with vascular cognitive impairment without dementia caused by subcortical ischemic small vessel disease: A multicentre, randomized, double-blind, placebo-controlled trial. Alzheimers Dement 12: 89-99, 2016.

6. Dong GX and Feng YP: Effects of NBP on ATPase and anti-oxidant enzymes activities and lipid peroxidation in transient focal cerebral ischemic rats. Zhongguo Yi Xue Ke Xue Yuan Xue Bao 24: 93-97, 2002 (In Chinese).

7. Chang Q and Wang XL: Effects of chiral 3-n-butylphthalide on apoptosis induced by transient focal cerebral ischemia in rats. Acta Pharmacol Sin 24: 796-804, 2003.

8. Li L, Zhang B, Tao Y, Wang Y, Wei H, Zhao J, Huang R and Pei Z: DL-3-n-butylphthalide protects endothelial cells against oxidative/nitrosative stress, mitochondrial damage and subsequent cell death after oxygen glucose deprivation in vitro. Brain Res 1290: 91-101, 2009.

9. Huang JZ, Chen YZ, Su M, Zheng HF, Yang YP, Chen J and Liu CF: dl-3-n-Butylphthalide prevents oxidative damage and reduces mitochondrial dysfunction in an $\mathrm{MPP}(+)$-induced cellular model of Parkinson's disease. Neurosci Lett 475: 89-94, 2010.

10. Wang HM, Zhang T, Huang JK and Sun XJ: 3-N-butylphthalide $(\mathrm{NBP})$ attenuates the amyloid- $\beta$-induced inflammatory responses in cultured astrocytes via the nuclear factor- $\mathrm{\kappa}$ signaling pathway. Cell Physiol Biochem 32: 235-242, 2013.

11. You J, Peng W, Lin X, Huang QL and Lin JY: PLC/CAMK IV-NF-kappaB involved in the receptor for advanced glycation end products mediated signaling pathway in human endothelial cells. Mol Cell Endocrinol 320: 111-117, 2010.

12. Ramasamy R, Yan SF and Schmidt AM: Receptor for AGE (RAGE): Signaling mechanisms in the pathogenesis of diabetes and its complications. Ann N Y Acad Sci 1243: 88-102, 2011.

13. Gerhardt T and Ley K: Monocyte trafficking across the vessel wall. Cardiovasc Res 107: 321-330, 2015.

14. Dragomir E and Simionescu M: Monocyte chemoattractant protein-1-a major contributor to the inflammatory process associated with diabetes. Arch Physiol Biochem 112: 239-244, 2006.

15. Holman RR, Paul SK, Bethel MA, Matthews DR and Neil HA: 10-Year follow-up of intensive glucose control in type 2 diabetes. N Engl J Med 359: 1577-1589, 2008

16. Nathan DM, Cleary PA, Backlund JY, Genuth SM, Lachin JM, Orchard TJ, Raskin P and Zinman B; Diabetes Control and Complications Trial/Epidemiology of Diabetes Interventions and Complications (DCCT/EDIC) Study Research Group: Intensive diabetes treatment and cardiovascular disease in patients with type 1 diabetes. N Engl J Med 353: 2643-2653, 2005.

17. Vlassara H, Fuh H, Donnelly T and Cybulsky M: Advanced glycation endproducts promote adhesion molecule (VCAM-1, ICAM-1) expression and atheroma formation in normal rabbits. Mol Med 1: 447-456, 1995.

18. Schmidt AM, Hori O, Chen JX, Li JF, Crandall J, Zhang J, Cao R, Yan SD, Brett J and Stern D: Advanced glycation endproducts interacting with their endothelial receptor induce expression of vascular cell adhesion molecule-1 (VCAM-1) in cultured human endothelial cells and in mice. A potential mechanism for the accelerated vasculopathy of diabetes. J Clin Invest 96: 1395-1403, 1995.

19. Schalkwijk CG and Stehouwer CD: Vascular complications in diabetes mellitus: The role of endothelial dysfunction. Clin Sci (Lond) 109: 143-159, 2005.

20. Khaira A, Mahajan S, Kumar A, Saraya A, Tiwari SC, Prakash S, Gupta A, Bhowmik D and Agarwal SK: Endothelial function and oxidative stress in chronic kidney disease of varying severity and the effect of acute hemodialysis. Ren Fail 33: 411-417, 2011.

21. Singh DK, Winocour $P$ and Farrington K: Oxidative stress in early diabetic nephropathy: Fueling the fire. Nat Rev Endocrinol 7: 176-184, 2011.

22. Rouhiainen A, Kuja-Panula J, Tumova S and Rauvala H: RAGE-mediated cell signaling. Methods Mol Biol 963: 239-263, 2013. 
23. Yan SF, Ramasamy R and Schmidt AM: The RAGE axis: A fundamental mechanism signaling danger to the vulnerable vasculature. Circ Res 106: 842-853, 2010.

24. Tang D, Kang R, Zeh HJ III and Lotze MT: High-mobility group box 1, oxidative stress, and disease. Antioxid Redox Signal 14 1315-1335, 2011

25. Peter ME: ROS eliminate danger. Immunity 29: 1-2, 2008.

26. Onat D, Brillon D, Colombo PC and Schmidt AM: Human vascular endothelial cells: A model system for studying vascular inflammation in diabetes and atherosclerosis. Curr Diab Rep 11: 193-202, 2011.

27. Lander HM, Tauras JM, Ogiste JS, Hori O, Moss RA and Schmidt AM: Activation of the receptor for advanced glycation end products triggers a $\mathrm{p} 21$ (ras)-dependent mitogen-activated protein kinase pathway regulated by oxidant stress. J Biol Chem 272: 17810-17814, 1997.

28. Marsche G, Semlitsch M, Hammer A, Frank S, Weigle B, Demling N, Schmidt K, Windischhofer W, Waeg G, Sattler W and Malle E: Hypochlorite-modified albumin colocalizes with RAGE in the artery wall and promotes MCP-1 expression via the RAGE-Erk1/2 MAP-kinase pathway. FASEB J 21: $1145-1152,2007$.
29. Thallas-Bonke V, Thorpe SR, Coughlan MT, Fukami K, Yap FY, Sourris KC, Penfold SA, Bach LA, Cooper ME and Forbes JM: Inhibition of NADPH oxidase prevents advanced glycation end product-mediated damage in diabetic nephropathy through a protein kinase $\mathrm{C}$-alpha-dependent pathway. Diabetes 57 : 460-469, 2008.

30. Xu D and Kyriakis JM: Phosphatidylinositol 3'-kinase-dependent activation of renal mesangial cell Ki-Ras and ERK by advanced glycation end products. J Biol Chem 278: 39349-39355, 2003.

31. Maugeri N, Rovere-Querini P, Baldini M, Sabbadini MG and Manfredi AA: Translational mini-review series on immunology of vascular disease: Mechanisms of vascular inflammation and remodeling in systemic vasculitis. Clin Exp Immunol 156: 395-404, 2009.

32. Libby P: Vascular biology of atherosclerosis: Overview and state of the art. Am J Cardiol 91: 3A-6A, 2003.

33. Szmitko PE, Wang CH, Weisel RD, Jeffries GA, Anderson TJ and Verma S: Biomarkers of vascular disease linking inflammation to endothelial activation: Part II. Circulation 108: 2041-2048, 2003. 